\title{
ANALISA KERUSAKAN CYLINDER HEAD PADA DIESEL ENGINE QSK 50 MCRS DI BENGKEL SUNGAI SEMBILAN NUNUKAN
}

\author{
Ismail Ramli, Al Amin, Muhammad Huzairi \\ Politeknik Negeri Nunukan Kalimantan Utara, Indonesia \\ Email: ismailramli001@gmail.com, alamin768@gmail.com, \\ muhhuzairi345@gmail.com
}

\begin{abstract}
Abstrak
Diesel Engine adalah motor bakar pembakaran dalam (Internal Combustion Engine), yang bahan bakarnya disemprotkan ke dalam ruang silinder pada waktu piston berada di titik mati atas (TMA). Penelitian ini bertujuan untuk mengetahui permasalahan yang terjadi pada kepala silinder, khususnya pada mesin QSK 50 MCRS, sehingga perawatan kepala silinder lebih baik, guna mengoptimalkan pengoperasian mesin dalam proses industri. Penelitian ini dilakukan untuk mendapatkan data guna mengetahui penyebab kerusakan kepala silinder pada mesin QSK 50 MCRS. Ada beberapa langkah yang dilakukan termasuk pembersihan, inspeksi visual, dan pengukuran dan analisis kerusakan pada kepala silinder. Hasil penelitian ini menunjukkan bahwa ada erosi selama proses pembersihan komponen. Ada kerusakan pada setiap permukaan ruang pembakaran di kepala silinder. Karakteristik kerusakan menunjukkan bahwa telah terjadi erosi kavitasi pada permukaan ruang pembakaran. Erosi kavitasi terjadi pada permukaan ruang pembakaran karena gelembung udara yang meledak atau meledak selama stroke daya dari siklus empat stroke mesin. Erosi kavitasi ditandai dengan permukaan dengan lubang kecil. Analisis kepala 16 silinder QSK 50 MCRS menunjukkan bahwa semua kepala silinder masih dapat digunakan lagi, karena kepala silinder masih dalam cakupan standar yang ditetapkan dalam manual.
\end{abstract}

Kata Kunci: kepala silinder; mesin; kerusakan

\section{Abstract}

Diesel engines are internal combustion engines, which fuel into the cylinder chamber at piston time at the top dead point (TMA). This study is in order to know which cylinder head is happening, especially in the QSK 50 MCRS engine, so that the maintenance of the cylinder head is better, in order to use it in the industry in the process. This research was conducted for data to determine the damage to the cylinder head in the QSK 50 MCRS engine. There are several steps which include conducting analysis, visual inspection, and analysis and analysis of damage to the cylinder head. The results of this study tyur, there is erosion during the process of creating components. There is damage to every surface of the chamber on the cylinder head. Damage is caused by cavity erosion to the surface of the flame. Cavitation erosion occurs on the surface of the living room while the area of air is or so objected to during the power stroke of the stroke machine of the fourth generation. Erosion of cavitation with surfaces with small holes. Analysis of the

$\begin{array}{ll}\text { How to cite: } & \text { Ramli, Ismail, Al Amin, Muhammad Huzairi (2021) Analisa Kerusakan Cylinder Head Pada Diesel } \\ & \text { Engine QSK 50 MCRS Di Bengkel Sungai Sembilan Nunukan, Syntax Idea, 3(7). https:// } \\ & \text { doi.org/10.36418/syntax-idea.v3i7.1381 } \\ \text { E-ISSN: } & \text { 2684-883X } \\ \text { Published by: } & \text { Ridwan Institute }\end{array}$


head of 16 cylinders QSK 50 MCRS field that all cylinder heads can still be times again, the cylinder head is still in control of the in-district in the manual.

Keywords: cylinder head; machine; damage

\section{Pendahuluan}

Perkembangan teknologi dan informasi merupakan sebuah keniscayaan. Kemajuan teknologi akan berjalan seiring dengan kemajuan ilmu pengetahuan dan kebutuhan manusia akan teknologi dan informasi. Berbagai inovasi diciptakan untuk memberikan manfaat positif bagi kehidupan manusia serta memberikan banyak kemudahan dalam melakukan aktifitas manusia (Wahyusetyawati, 2017).

Era globalisasi menuntut masyarakat modern untuk mempunyai mobilitas yang tinggi. Mobilitas yang tinggi tersebut mendorong tingginya kepadatan lalu lintas, baik barang maupun manusia di seluruh dunia. Melihat perkembangan yang ada dari kepadatan lalu lintas tersebut, semakin banyak ditemukan fakta yang menunjukkan bahwa jalan raya justru menjadi ladang pembunuhan manusia modern (Ariwibowo, 2013).

Mobilitas penduduk maupun barang akan terselenggara dengan menggunakan alat transportasi. Jumlah kendaraan bermotor cenderung meningkat dari tahun ke tahun. Salah satu alat transportasi yang paling banyak digunakan adalah kendaraan bermotor yakni jenis sepeda motor (Agustin, Gandhiadi, \& Oka, 2016).

Transportasi merupakan komponen utama dalam sistem hidup dan kehidupan, sistem pemerintahan, dan sistem kemasyarakatan. Kondisi sosial demografi s wilayah memiliki pengaruh terhadap kinerja transportasi di wilayah tersebut. Tingkat kepadatan penduduk akan memiliki pengaruh signifikan terhadap kemampuan transportasi melayani kebutuhan masyarakat. Di perkotaan, kecenderungan yang terjadi adalah menin gkatnya jumlah penduduk yang tinggi karena tingkat kelahiran maupun urbanisasi (Aminah, 2018).

Sepeda motor merupakan salah satu bidang usaha yang berkembang cukup pesat di negara Indonesia, seiring dengan meningkatnya jumlah penduduk yang membutuhkan transportasi sepeda motor. Saat ini banyak pabrik sepeda motor yang mengeluarkan produk dengan bermacam-macam merk dan desain sehingga membuat konsumen mempunyai banyak pilihan ketika ingin membeli sepeda motor (Nurjannah, Arifin, \& Khairina, 2015).

Diesel Engine adalah motor bakar pembakaran dalam (Internal Combustion Engine), yang bahan bakarnya disemprotkan ke dalam ruang silinder pada waktu piston berada di titik mati atas (TMA). Karena udara yang ada didalam silinder memiliki panas yang tinggi sehingga memudahkan bahan bakar yang telah diinjeksikan terbakar dengan sendirinya. Diesel engine pada umumnya memiliki komponen utama diantaranya adalah piston, valve, cranshaft, pompa bahan bakar yang bertekanan tinggi dan mekanisme penggerak lainnya. Energi yang dihasilkan diesel engine di dapat melalui pembakaran bahan bakar yang terjadi di dalam silinder. Hal ini menyebabkan pemindahan gerakan 
piston di dalam silinder yang dihubungkan dengan cranshaft pada bantalannya melalui batang penghubung (Connecting Rod) (Zamimah, 2018).

Cylinder head merupakan bagian dari blok silinder yang berfungsi untuk menutup rongga silinder, dimana ruang tersebut merupakan ruang pembakaran. Dengan adanya cylinder head ini maka pembakaran didalam ruang selinder dapat terjadi. Blok silinder disebut sebagai base engine part atau sebuah komponen utama dari engine. cylinder Head disebut second base karena komponen ini menjadi basis beberapa komponen yang ada pada engine bagian atas. Cylinder head akan menerima beban yang berat karena menahan tekanan kompresi, sehingga di dalam pemakaiannya akan terjadi beberapa kerusakan pada bagian ini (Hadi, 2016).

Cylinder Head merupakan mesin yang sering mengalami breakdown pada tahun 2013 yaitu sebanyak 56 kali. Kerusakan tersebut tentu saja mempengaruhi kegiatan produksi perusahaan, menyebabkan turunnya produktivitas perusahaan (Rumita, Nugroho WP, \& Putri Nur H, 2014).

Kerusakan yang bisa terjadi pada cylinder head antara lain packing cylinder head rusak yang mengakibatkan kompresi bocor dan engine tidak berfungsi sebagaimana mestinya, kerusakan bisa terjadi pada hubungan antara 2 cylinder atau pada hubungan oli dan air, yang mengakibatkan engine menjadi kurang berfungsi. Cylinder head mengalami keretakan biasanya terjadi pada diesel engine, keretakan yang terjadi karena panas berlebih (over heat), dimana engine terlalu panas yang diakibatkan oleh muatan yang berlebihan atau sistem pendinginan mengalami kerusakan atau kebocoran salahsatunya. Keretakan juga sering disebabkan karena tidak berfungsinya thermosat dimana pada saat suhu meningkat thermosat tidak terbuka (Widodo, 2018).

\section{Metode Penelitian}

Penelitian ini bertujuan untuk mengetahui apakah dalam analisis cylinder head QSK 50 MCRS masih memenuhi standar sesuai dengan buku panduan dan untuk mengetahui bagaimana cara meminimalisir kerusakan pada cylinder head (Gemely, 2018). Adapun tahapan proses dalam menganalisa kerusakan dapat dilihat pada gambar di bawah ini

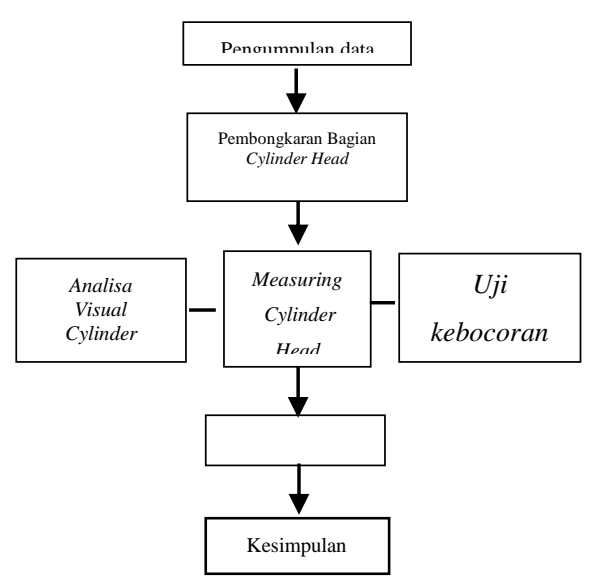




\section{Prosedur umum melakukan cleaning, visual inspection, dan measuring}

Berikut adalah cara melakukan cleaning, berdasarkan petunjuk yang diketahui di perusahaan tempat melakukan penelitian dimana diberikan petunjuk tentang cara melakukan cleaning visual inspection dan measuring cylinder head.

1. Bersihkan cylinder head dari sisa gasket yang menempel.

2. Ukur ketebalan cylinder head pada setiap ruang bakar.

3. Ukur kerataan permukaan area ruang bakar.

4. Periksa area pembakaran dari retakan atau kebocoran.

5. Periksa area pembakaran dari kerusakan dan erosi.

Re-kondisi komponen yang membutuhkan perbaikan dan ganti bagian-bagian yang tidak memenuhi spesifikasi.

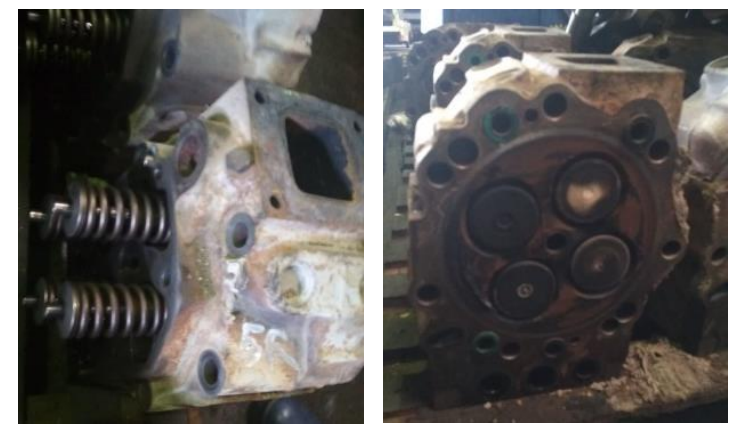

Gambar 1

\section{Re-kondisi komponen}

\section{Hasil dan Pembahasan}

\section{Analisa Visual Cylinder Head}

Pada saat dilakukan proses cleaning component ditemukan kerusakan disetiap permukaan ruang bakar pada cylinder head. Ciri-ciri kerusakan tersebut menunjukan bahwa telah terjadinya "erosi" pada permukaan ruang bakar, erosi terjadi pada permukaan ruang bakar karena adanya gelembung udara yang pecah atau meledak saat langkah usaha (power) pada siklus empat langkah engine. Erosi ditandai dengan permukaan yang berlubang - lubang kecil. Fenomena cacat shrinkage porosity tersebut disebabkan oleh adanya inklusi oksida aluminium yang terbawa ke dalam produk Cylinder Head Type-A yang menjadi inisiasi terbentuknya shrinkage porosity. Terdapatnya oksida aluminium pada produk Cylinder Head Type-A disebabkan oleh waktu transfer molten dari melting furnace yang relatif lama dan jarak auto carrier yang relatif tinggi sehingga turut mempengaruhi waktu pouring ke holding furnace (Wahyudi \& Wiryolukito, 2020).

Ketika gelembung-gelembung ini memasuki daerah bertekanan tinggi, mereka pecah (meledak menuju ke dalam) mengirim sebuah "pancaran" cairan membentur permukaan logam dengan kecepatan supersonic. Keretakan kecil 
kadang-kadang terjadi dan bergabung sampai sebagian kecil partikel logam terlepas dan mengakibatkan lubang pada komponen.

Pitted/pitting yang dalam pada permukaan liner adalah akibat dari erosi kavitasi. Kerusakan terkumpul pada satu area dari dinding liner saja. Fakta pada saat pembongkaran menyatakan bahwa area yang rusak terletak antara cylinder head dan permukaan liner.

Aluminium housing pada sistem pendingin dapat dirusak oleh erosi kavitasi, khususnya jika terdapat hambatan pada saluran isap/masuk yang mengakibatkan tekanan rendah dan berikutnya menyebabkan kavitasi fluida pada impeller pompa. Gelembung (bubble) yang terbentuk pada sisi low pressure (suction/isap) akan pecah pada sisi high pressure (discharge/pengeluaran). Penggunaan logam pengisi pada teknik powder thermal spray masih menggunakan logam yang berbeda sehingga kategori penyambungan termasuk kedalam dissimilar metal. Oleh sebab itu, masalah penting yang harus dipecahkan adalah bagaimana memperbaiki cacat coran dengan cara mengeliminir kelemahan-kelemahan perbaikan dengan metodemetode yang telah dikembangkan selama ini (Pengarah, 2012). Pada gambar 1 menunjukan erosi pada cylinder head.

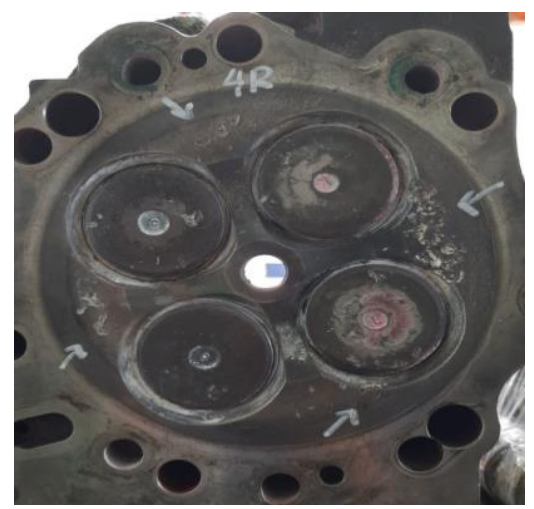

Gambar 2

2. Pengukuran Data Aktual

\section{Erosi pada cylinder head}

\section{Ketebalan dan Panjang Cylinder Head}

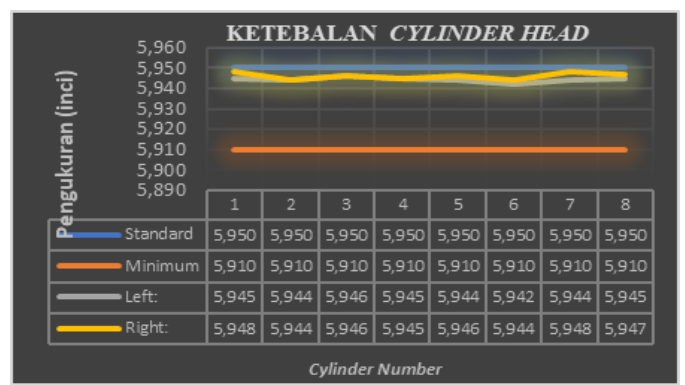

Gambar 2

Hasil pengukuran ketebalan cylinder

head 
Berdasarkan data pada Gambar 2, maka ketebalan cylinder head masih memenuhi standar karena hasil pengukuran masih di atas standar ketebalan cylinder head minimum.

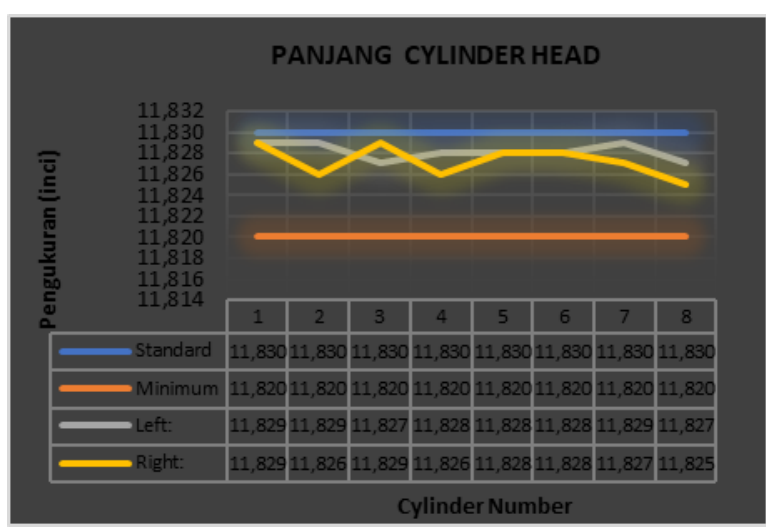

Gambar 3

Hasil pengukuran panjang cylinder head

Berdasarkan data pada Gambar 3, dapat dilihat bahwa panjang cylinder head masih memenuhi standar, karena hasil pengukuran masih di atas standar panjang cylinder head minimum.

\section{Pengukuran Pitting Cylinder Head}

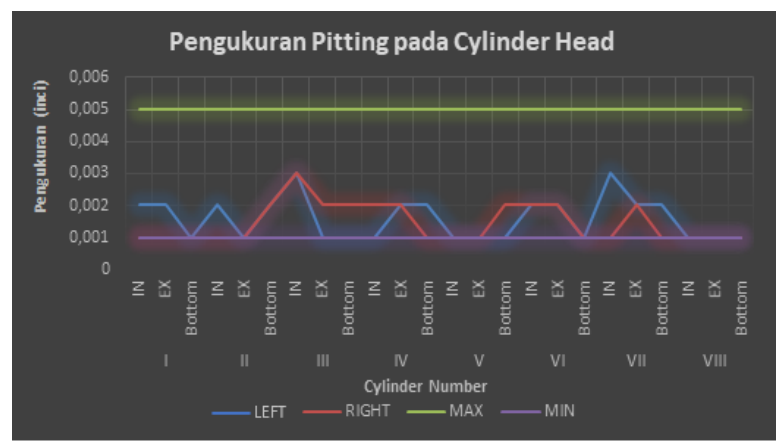

Gambar 4

Hasil pengukuran panjang cylinder head

Hasil pengukuran tersebut menunjukkan bahwa cylinder head masih memenuhi standard dan dapat digunakan kembali, karena nilai pengukuran pitting masih berada di bawah nilai maksimum.

\section{Tes Kebocoran (Pressure Test Cylinder Head)}

Setelah dilakukan pengujian diperoleh hasil yang menunjukkan bahwa tidak terjadi kebocoran pada lubang valve. Selain pressure test, dilakukan juga pemeriksaan visual terhadap cylinder head untuk memeriksa:

a. Rusaknya baut-baut / stud.

b. Korosi pada sambungan selang.

c. Kebocoran-kebocoran oli. 
d. Selang-selang vakum rusak / hilang.

e. Kebocoran-kebocoran cairan pendingin.

Spil Nita adalah terjadinya water hammer atau hentakan air yang terjadi karena penekanan piston ketika akan mengkompresikan udara dan bahan bakar yang mengakibatkan tekanan pada air sehingga bagian mesin yang berhubungan dengan sistem pembakaran terjadi kerusakan. Perbaikan dan perawatan yang dilakukan untuk mencegah terjadinya kebocoran di ruang pembakaran (Hutama, 2019).

\section{Kesimpulan}

Berdasarkan hasil dan pembahasan dalam penelitian mengenai Analisis Kerusakan Cylinder Head Pada Engine QSK 50 MCRS diperoleh kesimpulan sebagai berikut. Pertama, Analisis terhadap 16 cylinder head QSK 50 MCRS menunjukkan bahwa seluruh cylinder head masih dapat digunakan kembali, karena cylinder head tersebut masih berada dalam cakupan standar yang telah ditetapkan pada buku panduan. Kedua, Untuk penggunaan cylinder head lebih lama, sebaiknya harus dicegah dari kerusakan yang lebih fatal dengan melakukan service secara berkala. Oleh karena itu, dalam proses assembly dan perawatan dari cylinder head merupakan hal yang penting dan dalam proses assembly harus sesuai dengan prosedur yang telah ditetapkan di dalam buku panduan. 


\section{BIBLIOGRAFI}

Agustin, Ami Hilda, Gandhiadi, G. K., \& Oka, Tjokorda Bagus. (2016). Penerapan Metode Fuzzy Sugeno Untuk Menentukan Harga Jual Sepeda Motor Bekas. EJurnal Matematika, 5(4), 1751-2303.Google Scholar

Aminah, Siti. (2018). Transportasi Publik dan Aksesbilitas Masyarakat Perkotaan. Jurnal Teknik Sipil, 9(1), 1142-1155. Google Scholar

Ariwibowo, Raditya. (2013). Hubungan antara umur, tingkat pendidikan, pengetahuan, sikap terhadap praktik safety riding awareness pada pengendara ojek sepeda motor di Kecamatan Banyumanik. Jurnal Kesehatan Masyarakat Universitas Diponegoro, 2(1), 18819. Google Scholar

Gemely, Delfani. (2018). Implementasi Sistem Manajemen Keselamatan Dan Kesehatan Kerja Di PT. Pelindo IV (Persero) Terminal Petikemas Makassar Tahun 2018. Jurnal Kesehatan Masyarakat Mulawarman (JKMM). Google Scholar

Hadi, E. K. O. Prasetyo. (2016). Rancang Bangun Alat Bantu Pengujian Tekanan Pada Injector Nozzle (Proses Perancangan). Politeknik Negeri Sriwijaya. Google Scholar

Hutama, Viergian Istanto. (2019). Analisis Penyebab Terjadinya Kebocoran Air Di Ruang Pembakaran Pada Diesel Generator Di Km. Spil Nita. Politeknik Ilmu Pelayaran Semarang. Google Scholar

Nurjannah, Nency, Arifin, Zainal, \& Khairina, Dyna Marisa. (2015). Sistem pendukung keputusan pembelian sepeda motor dengan metode weighted product. J. Inform. Mulawarman, 10(2), 2-6. Google Scholar

Pengarah, Panitia. (2012). Dewan Redaksi. Google Scholar

Rumita, Rani, Nugroho WP, Susatyo, \& Putri Nur H, Sri Radina. (2014). Analisis Repair Policy Dan Preventive Maintenance Policy Untuk Mengetahui Biaya Yang Optimal Pada Mesin Mv-40 Line Cylinder Head Pt. Kubota Indonesia. Proceedings 1st Annual Conference In Industrial And System Engineering (ACISE) 2014. Teknik Industri Universitas Diponegoro. Google Scholar

Wahyudi, Wahyudi, \& Wiryolukito, Slameto. (2020). Analisis Gagal Leak Test Pada Produk Cylinder Head Type-A Hasil Proses Low Pressure Die Casting Dengan Material Ac4b Di Pt. X. Technologic, 11(2). Google Scholar

Wahyusetyawati, Endang. (2017). Dilema pengaturan transportasi online. Jurnal RechtsVinding. ISSN, 2089-9009. Google Scholar

Widodo, Sigit. (2018). Perancangan Engine Mini Bike Dengan Menggunakan Motor Bensin. Institut Teknologi Nasional Malang. Google Scholar 
Ismail Ramli, Al Amin, Muhammad Huzairi

Zamimah, Iffati. (2018). Moderatisme Islam dalam konteks keindonesiaan. Jurnal AlFanar, 1(1), 75-90. Google Scholar

\section{Copyright holder:}

Ismail Ramli, Al Amin, Muhammad Huzairi (2021)

\section{First publication right:}

Syntax Idea

This article is licensed under:

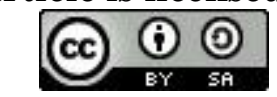

